\title{
Web Enabled Remote Toxic Gas Monitoring and Controlling System
}

\author{
Suraj Metkar \\ Student \\ Late G.N.Sapkal College of \\ Engineering, Anjaneri, Nashik
}

\author{
Pankaj Khapare \\ Student \\ Late G.N.Sapkal College of \\ Engineering, Anjaneri, Nashik
}

\author{
Amit Palve \\ Assi. Prof. at Late G.N.Sapkal \\ College of Engineering \\ Anjaneri, Nashik
}

\begin{abstract}
This project is about designing a system which will help to reduce the global warming and greenhouse effect. The main aim of this project is to monitor and control each and every industry present in the state for their limitless toxic gas emission in the environment. This project contain back end MS SQL database and front end asp.net. In the system there is a sensor (MQ6) installed in the chimneys of the industries which will help in detection of harmful gasses. Every industry is installed with a server which will help in comparison of the data taken from the sensor to monitor whole system. The system consists of a centralized database storing unit for storing all the information about every industry in the respective state.

If the industry emits large amount of harmful gases then the mq6 sensor will detect this activity and will fire a buzzer. Still then the company did not stop to produce the harmful gases in the surrounding then the buzzer will buzz for the final time and the system will automatically shut down the power supply of the industries which leads in blocking of boiler. The employee sitting in collector council office has given extra functionality to monitor every aspect of company's gas emission rate and report to that industry about their extensive emission of harmful gases beyond their available limit.
\end{abstract}

\section{Keywords}

Toxic gas emission, MQ6 sensor, global warming, monitoring and controlling system, Measurement, toxicity, sequence step algorithm.

\section{INTRODUCTION}

The devastating and disastrous effect of the global warming helped to think about the problem in existing system. Lot of thinking is done about how to modify or else change the aspect of whole system in a convenient manner to be implied on the collector council employees in the respective state. By studying the existing system of the government it was concluded that there should be a real time software project to be based on remote toxic gas monitoring and controlling system. In existing scenarios there was a government employee which was appointed who has a duty to go in each and every industries and note the emission ratio at that current time.

The proposed system is to develop a new system which should be web enabled, works remotely and which monitors and controls the industrial toxic gas emission in the environment. Thus the proposed new design for the system is going to overcome the challenges and issues of existing system.

\subsection{Detailed problem definition}

In our proposed system there will be a server having back end MS SQL for database related activity and the MQ6/ CO2 sensor to be fitted in the top of chimneys[1]. This sensor will continuously record the toxicity of gas and store them in the form of data in the database of server. If particular industries produces large amount of goods by burning fuel and emitting huge amount of harmful gases $(\mathrm{CO} 2, \mathrm{CH} 4$, etc.) in the environment then the MQ6 sensor fitted in chimneys of industries will compare the current emission ratio with the threshold value allocated by the government[2]. If the industry's emission ratio is greater than maximum allowed value the system will warn the industry with the help of buzzer[2].

The proposed system is designed in such a way that the industries can cross the maximum threshold value only three times a day. If still after the third buzzer the industry began to emit toxic gases in the environment then a final warning will be given to the industry and the system will cut the electricity supply of that industry. The shutdown of the electric supply will ultimately block the boiler and the industry can be stopped from emitting harmful toxic gases in the environment[2]. The extra functionality provided by the project is that the person sitting in the collector office will be able to monitor remotely and control all the industries emitting toxic gas in the atmosphere. There is also a centralized server provided in the network for storing and taking the entire backup into that database.

\section{OBJECTIVE \& SCOPE}

The system is designed by keeping in mind various disastrous effect of the global warming on human health and environment. The main motto of the system is to be operable for 24hours/day and 7 days/week without unnecessary spurious alarms. The main objective functionality about the system is that, the systems will shut down the Electricity supply of an industrial plant on the basis of exceeding threshold value. The system has the extra special functionality that the system will provide gas cabinet status to various locations around the industrial plant as well as to the main server in the office[1]. If the threshold value of the industries emission ratio remains lower than the maximum allowed value by the government then the whole system will be able to control the pollution in the environment.

As the project will show its best performance and its efficiencies in controlling the pollution in the environment, lot more different application region where it is needed can be found out. There are some extra plan for the system to be implemented in future such as adding an additional functionality modules such as implementation of High Definition Web camera to lively monitor the specific industry 
and the second important additional functionality is Temperature Sensor can be added with existing module[1].

\section{SURVEY OF LITERATURE \\ 3.1. Existing System}

In the current scenario to specify the existing system there is a person appointed by Government in every state, who is responsible for collecting information or it can be said that gathering emission ratio and all toxicity related values from each and every industry present in his area of work. The existing system contains the employee who goes to industries and cross check the values of current emission ratio against the threshold value allocated by the government. The chances to fool the government employee were very high because the owner of the industry would slow down the emission of toxic gases only at the time when the government employee comes for inspection.

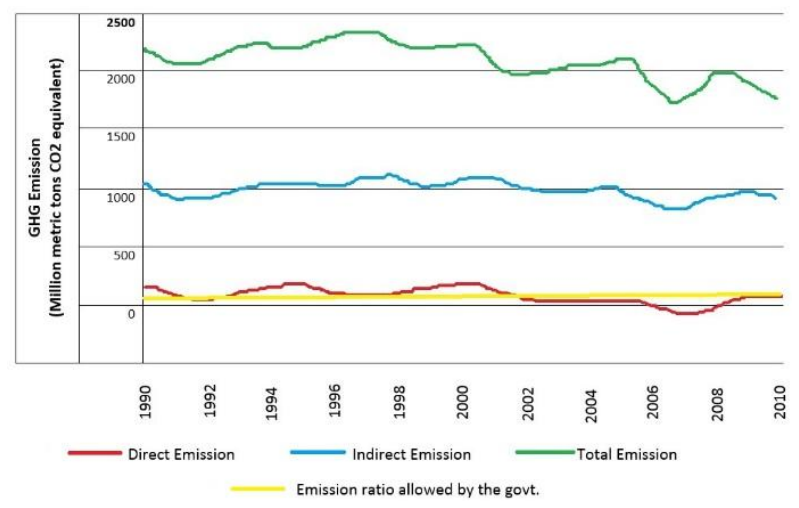

Figure 1: Emission ratios

Figure1 shows that the existing system can be easily cheated and is not much reliable and also it does not contain proper workflow. The existing system had become the place where corruption and bribes can take place in large ratio. So to reduce the chances of corruption and to bring a transparent behavior in the system it was necessary to develop a new project which could help the system to be much more reliable and efficient.

\subsection{Proposed System}

In this paper it was a need to think and consider the global issues related to environment that is global warming, air pollutions, greenhouse effect and different types of chemical hazards. Due to this issue there are lot more consequences detected to human health and ultimately to the environment. It has been seen that the people living in the area where industries are located have less life span than an ordinary people present in natural environment. Most of these people are also suffering from severe diseases such as cancer, asthma, pneumonia, bronchitis, etc.

To overcome all the drawbacks of the existing system and to improve human health present in the industrial area it was need to develop a new project based on web technology and windows application platform[1]. The development of the project is in field of embedded systems. The project contains electronics components such as micro controller, sensor circuitry and relay circuitry[1]. The microcontroller is responsible for handling the threshold emission ratio value and current emission ratio value. Sensor circuitry present consists of MQ6 sensor which has its main task to sense the emission ratio of industry and pass the value to microcontroller for comparing[2]. Relay circuitry is used for switching OFF the electricity supply of the industry. The project consists of a provision given to the employee present in the collector office to access and monitor all the emission ratio of the industry present in the area.

\section{SYSTEM ARCHITECTURE}

The system architecture consists of the electronic components such as microcontroller, sensor circuitry and relay. The overview of system is shown in the figure2.

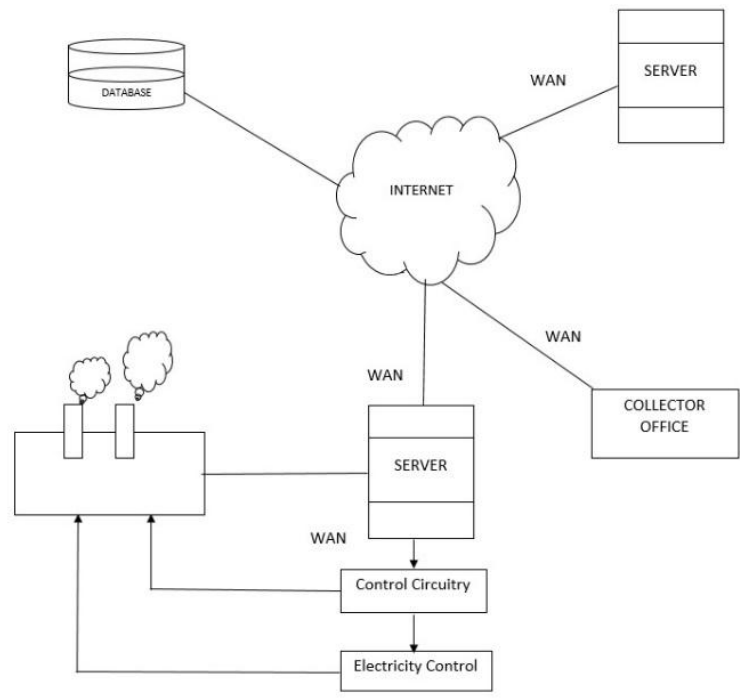

Figure 2: System architecture.

There are 4 main blocks in the system and they are industry local server, main server, centralized database, admin GUI.

\subsection{Implementation}

System has four main components which are independent from each other. Firstly of all the input to the system is given through the sensor component fitted in the chimneys of the industries. The sensor present is MQ6 and which is used for recording emission ratio values from the toxicity of the gas[2]. The MQ6 sensor has a responsibility for continuously gathering the current toxic emission ratio value and passing the inputs to microcontroller to perform further activities.

The input from the sensor is recognized by the microcontroller and it is compared against the standard threshold value of the emission ratio allocated by the government. If the current emission ratio is found to be greater than allocated value the buzzer[2] is buzz out for three times and the industries is expected to slow down the emission ratio values. But if the industries continue to produce the toxic gas beyond the threshold value a relay circuitry comes into picture and does a job of shutting down the power supply of the industries. These shutting down operation can also be controlled by the employee sitting in the collector's office.

\subsection{Flow Chart of the Sequence Step Algorithm}

A sequence step algorithm (SQS-AL) is an algorithm implemented in a discrete event simulation system to maximize utilization of the resources. This is achieved by running through two main nested loops: A sequence step loop and a replication loop. For each sequence step, simulation designed for replication loop run that get crew idle time for activities in that sequence step. The resource arrival dates for user-specified confidence levels are determined by the 
collected crew idle times. The process of collecting the crew idle times and determining crew arrival times for activities are considered as a sequence step which is repeated from the first to the last sequence step.

\subsection{Technology Used}

\subsubsection{Vb.net}

Vb.net technology is used in the system to design the GUI (graphical user interface) for communicating with the system. The .NET is similar to Java because it uses an intermediate byte code language that can be executed on any hardware platform that has a runtime engine. As the system is embedded hence vb.net technology is suitable for it. .NET is also unlike Java, as it provides support for multiple programming languages. Microsoft languages are C\# (C Sharp), J\# (J Sharp), Managed C++, JScript.NET and Visual Basic.NET. Other languages have been reengineered in the European version of .NET, called the Common Language Infrastructure. The .NET compilers generate Microsoft Intermediate Language (MSIL) byte code, which is executed by the .NET Common Language Runtime engine.

\subsubsection{C++ micro- controller coding}

$\mathrm{C}++$ is one of the most popular programming languages and is implemented on a wide variety of hardware and operating system platforms. The language has an efficient compiler for native code. The application domains include system software, application software, embedded software, device drivers, high-performance server and client applications, and entertainment software such as games. The coding in $\mathrm{C}++$ is done in micro controller for storing the maximum threshold value of gas and current emission ratio value. The coding has main objective of comparing the current emission ratio value with standard value allowed[2]. The shutting down signal to the relay circuitry is been controlled by micro controller. $\mathrm{C}++$ had greatly influenced many other popular programming languages, most notably $\mathrm{C \#}$ and java so it is feasible for the use in micro controller.

\section{COMPONENT DESIGN 5.1 MQ6 modem details}

MQ-6 is semiconductor sensor for gas sensitive material of is $\mathrm{SnO} 2$, which with lower conductivity through clean air[2]. The MQ6 sensor is located where there is target emission of combustible gas. As the concentration of the toxic gas rises the conductivity of the sensor also increases. The change in the conductivity[2] of the sensor is then used for conversion into electrical output signal. MQ-6 gas sensor has high sensitivity to Propane, Butane and LPG, also response to Natural gas. The sensor could be used to detect different types of combustible gases especially Methane[1]. MQ6 sensor is available with low cost and suitable for different application.

\section{- Character Configuration}

$>$ Good sensitivity to Combustible gas in wide range

$>$ High sensitivity to Propane, Butane and LPG

$>$ Long life and low cost

$>$ Simple drive circuit
- Application

$>$ Domestic gas leakage detector

$>$ Industrial Combustible gas detector

$>$ Portable gas detector

\section{ACKNOWLEDGMENTS}

We could never have completed our paper without the support and assistance of many people. First and foremost, we would like to express deepest gratitude to our project guide Prof. Amit H. Palve for his excellent guidance, valuable suggestions and kind of encouragement in academics.

We would also like to thank Prof. Santosh R. Durugkar as they have given us time to time information about the paper. We are grateful for their help. We are thankful to our HOD Prof. N. R. Wankhade and Principle Dr. Basavraj V. Balapgol for providing us this infrastructure and labs.

Last but not the least we owe a debt to our parents who are the silent guides in our life. We are also thankful to We are also thankful to all our friends for their encouragement and support.

\section{CONCLUSION}

It is concluded that the analysis of the non-efficient existing system and researches about toxicity management systems will be of great use to the society. The real time running prototype of the system will be accurate, reliable and more over would keep a strong control of government on the industries producing limitless toxic gases. As the project is based on web technologies hence the project provides special functionality for the employee. The employee can login from any computer system present anywhere of the state to keep an eye on the emission ratio of the industries and can take collective actions accordingly on the owner of industries immediately.

The development of this new idea will give a boon to technological fields and lot more ideas can be thought in accordance with this project. The project has a wide future scope and can be implemented in many systems like domestic gas leakage detection system, water toxicity detection system, etc. The project has high adaptability because if the sensors are replaced the area of work can be easily changed by keeping all the circuitry same for example if the MQ6 sensor is replaced by fire detection sensor, the project will work as fire alarming system.

\section{REFERENCES}

[1] Zhongliang $\mathrm{Fu}$, Yuefeng $\mathrm{Lu}$ "Reasearch on toxic gas monitoring systm based on sensorGIS" School of Remote Sensing and Information Engineering, Wuhan University Wuhan, China

[2] C. Liu, P. Zhang, "A Discussion on the Design of Detection and Alarm System for Combustible and Toxic Gas," Automation in Petro-Chemical Industry, vol. 6, pp.1-4, 2006. 